\title{
Does Medicaid Insurance Confer Adequate Access to Adult Orthopaedic Care in the Era of the Patient Protection and Affordable Care Act?
}

\author{
Joseph T. Labrum IV BA, Taylor Paziuk BS, Theresa C. Rihn BS, JD, \\ Alan S. Hilibrand MD, Alexander R. Vaccaro MD, PhD, MBA, \\ Mitchell G. Maltenfort PhD, Jeffrey A. Rihn MD
}

Received: 30 October 2016/ Accepted: 24 January 2017/Published online: 21 February 2017

(C) The Association of Bone and Joint Surgeons (B) 2017

\begin{abstract}
Background A current appraisal of access to orthopaedic care for the adult patient receiving Medicaid is important, since Medicaid expansion was written into law by the Patient Protection and Affordable Care Act (PPACA).

Questions/Purposes (1) Do orthopaedic practices provide varying access to orthopaedic care for simulated patients with Medicaid insurance versus private insurance in a blinded survey? (2) What are the surveyed state-by-state Medicaid acceptance rates for adult orthopaedic practices in the current era of Medicaid expansion set forth by the PPACA? (3) Do
\end{abstract}

Each author certifies that he or she has no commercial associations (eg, consultancies, stock ownership, equity interest, patent/licensing arrangements, etc) that might pose a conflict of interest in connection with the submitted article.

All ICMJE Conflict of Interest Forms for authors and Clinical Orthopaedics and Related Research ${ }^{\mathbb{R}}$ editors and board members are on file with the publication and can be viewed on request.

Each author certifies that his or her institution approved or waived approval for the human protocol for this investigation and that all investigations were conducted in conformity with ethical principles of research.

This work was performed at Thomas Jefferson University, Philadelphia, PA, USA.

J. T. Labrum IV, T. Paziuk

Sidney Kimmel Medical College, Thomas Jefferson University,

Philadelphia, PA, USA

T. C. Rihn

Jefferson College of Biomedical Sciences, Thomas Jefferson

University, Philadelphia, PA, USA

A. S. Hilibrand, A. R. Vaccaro, M. G. Maltenfort,

J. A. Rihn $(\bowtie)$

The Rothman Institute, Thomas Jefferson University Hospital, 925 Chestnut St., 5th Floor, Philadelphia, PA 19107, USA

e-mail: jrihno16@yahoo.com surveyed rates of access to orthopaedic care in the adult patient population vary across practice setting (private vs academic) or vary with different Medicaid physician reimbursement rates? (4) Are there differences in the surveyed Medicaid acceptance rates for adult orthopaedic practices in states that have expanded Medicaid coverage versus states that have foregone expansion?

Methods Simulated Patient Survey: We performed a telephone survey study of orthopaedic offices in four states with Medicaid expansion. In the survey, the caller assumed a fictitious identity as a 38-year-old male who experienced an ankle fracture 1 day before calling, and attempted to secure an appointment within 2 weeks. During initial contact, the fictitious patient reported Medicaid insurance status. One month later, the fictitious patient contacted the same orthopaedic practice and reported private insurance coverage status. National Orthopaedic Survey: Private and academic orthopaedic practices operating in each state in the United States were called and asked to complete a survey assessing their practice model of Medicaid insurance acceptance. State reimbursement rates for three different Current Procedural Terminology $\left(\mathrm{CPT}^{\mathbb{R}}\right)$ codes were collected from state Medicaid agencies. Results Simulated Patient Survey: Offices were less likely to accept Medicaid than commercial insurance (30 of 64 [47\%] versus 62 of 64 [97\%]; odds ratio [OR], 0.0145; 95\% CI, $0.00088-0.23639 ; \mathrm{p}<0.001$ ), and patients with Medicaid were less likely to be offered an appointment within 2 weeks (23 of 64 [36\%] versus 59 of 64 [89\%]; OR, 0.0154; 95\% CI, 0.00094- 0.251; $p<0.001)$. The Medicaid acceptance rates observed across states sampled in the simulated patient survey were 67\% (Pennsylvania), 21\% (New Jersey), 58\% (Delaware), and 50\% (Maryland) $(\mathrm{p}=0.04)$. National Orthopaedic Survey: Adult patients with Medicaid insurance had limited access to care in 109 
of $342(32 \%)$ orthopaedic practices: $37 \%$ of private and $13 \%$ of academic practices $(\mathrm{p}<0.001)$. Practices that accepted Medicaid received higher reimbursement for each CPT $^{\circledR}$ code relative to those that did not and acceptance of Medicaid became increasingly more likely as reimbursement rates increased (99243: OR, 1.03, 95\% CI, 1.02-1.04 per dollar, $\mathrm{p}<0.001$; 99213: OR, 1.05; 95\% CI, 1.03-1.07 per dollar, $\mathrm{p}<0.001$; 28876: OR, 1.01, 95\% CI, 1.00-1.01 per dollar, $\mathrm{p}<0.001)$. For a given reimbursement rate, private practices were less likely to take an adult patient with Medicaid relative to an academic practice (99243: OR, 0.11, 95\% CI, 0.04-0.33, p < 0.001; 99213: OR, 0.11, 95\% CI, 0.04-0.32, p < 0.001; 27786: OR, 0.12, 95\% CI, $0.04-0.35, \mathrm{p}<0.001)$. No difference was observed when comparing Medicaid acceptance rates for all practice types between states that have expanded their Medicaid program versus those that have not (OR, 1.02; 95\% CI 0.62-1.70; $\mathrm{p}=0.934)$.

Conclusions In this two-part survey study, we found that a simulated patient with commercial insurance was more likely to have their insurance accepted and to gain timely access to orthopaedic care than a patient with Medicaid. Academic practice setting and increased Medicaid reimbursement rates were associated with increased access to care for the patient with Medicaid. Inequality in access to orthopaedic care based on health insurance status likely exists for the adult patient with Medicaid. Furthermore, Medicaid expansion has likely realized minimal gains in access to care for the adult orthopaedic patient. Further research is needed in delineating the patient-payer selection criteria used by orthopaedic practices to aid policymakers in reforming the Medicaid program and comprehensibly addressing this access to care disparity.

Level of Evidence Level II, prognostic study.

\section{Introduction}

The Patient Protection and Affordable Care Act (PPACA, also known as Obamacare), passed in 2009, expanded Medicaid eligibility to individuals with incomes up to $138 \%$ of the federal poverty level. Since 2012, state Medicaid and Children's Health Insurance Program (CHIP) enrollment in these programs has increased more than $25 \%$ nationally as of $2015[2,12]$. A central tenet of the PPACA was the belief that increased Medicaid eligibility would result in improved access to healthcare and improved outcomes for the uninsured and underinsured [12]. Before passage of the PPACA, several studies found that adult patients with Medicaid experience poorer continuity of care, delayed diagnoses, and worse outcomes than their counterparts with private insurance $[3,9,19]$.
Although these studies show poor access and inferior outcomes for patients with Medicaid before the PPACA, there are little data regarding whether the expansion of coverage to previously uninsured groups has resulted in improved access or care. Because a majority of the almost 12 million new patients who went from no insurance to insured received their coverage through Medicaid (92\%), we sought to determine whether orthopaedic patients would face fewer impediments to care [5]. The primary objectives of this two-part study are to (1) assess access to care for the adult patients with Medicaid with an acute ankle fracture in states with Medicaid expansion, (2) assess state-by-state differences in Medicaid acceptance rates, (3) assess the effect of physician reimbursement rate and orthopaedic practice construct on access to orthopaedic care for the patient with Medicaid, and (4) determine the effect of Medicaid expansion under the PPACA on access to orthopaedic care for the patient with Medicaid.

We therefore asked: (1) Do blinded, surveyed orthopaedic practices provide varying access to orthopaedic care for simulated patients with Medicaid insurance versus private insurance? (2) What are the surveyed state-by-state Medicaid acceptance rates for adult orthopaedic practices in the current era of Medicaid expansion set forth by the PPACA? (3) Do surveyed rates of access to orthopaedic care in the adult patient population vary across practice setting (private vs academic) or vary with different Medicaid physician reimbursement rates? (4) Are there differences in the surveyed Medicaid acceptance rates for adult orthopaedic practices in states that have expanded Medicaid coverage versus states that have foregone expansion?

\section{Methods}

Study Design and Setting

\section{Participant-blinded Simulated Patient Survey}

Orthopaedic offices were identified from an online search via Yellow pages ${ }^{\mathrm{TM}}$ (YP.com; http://www.yellowpages.com) for "Orthopedic surgeon" within 100 miles in Pennsylvania (Philadelphia), New Jersey (Trenton), Delaware (Newark), and Maryland (Baltimore) in the creation of a multistate survey sample population. Repeat listings were excluded and any practice that was self-described on the listing as nonsurgical was excluded. The design of this study component was based on the 2014 study by Pierce et al. [14].

\section{National Orthopaedic Practice Survey}

A study design similar to that published by Skaggs et al. [16] was used in this current nationwide telephone survey 
study. The orthopaedic practice list for each state was generated via a Google search delegated: "Orthopaedic Surgery + State". After generating a practice list with a target of 10 private and four academic institutions for each state, a random number was assigned to each practice. These numbers were subsequently used to select the practices that would be contacted to represent each state in ascending order. Study design followed the construct used by Skaggs et al. [16]: Seven practices, two academic and five private, were selected from each state. If a practice on the original list could not be contacted, the practice that was next on the preliminary list was substituted. If a state did not meet the two academic practice requirement, another private practice was added such that the total state representation was seven.

\section{Description of Experiment, Treatment or Surgery}

\section{Participant-blinded Simulated Patient Survey}

Orthopaedic offices in Pennsylvania, New Jersey, Delaware, and Maryland were contacted twice via telephone to secure an appointment within 2 weeks of contact. The calls were placed 1 month apart. The caller assumed a fictitious identity as a 38-year-old male who experienced an ankle fracture 1 day before calling. The caller attempted to obtain an appointment within 2 weeks using the following script: "Hi, I was seen in the emergency room after I fell yesterday and I was told that I have a fractured ankle. I was told that I needed to be seen by an orthopaedic surgeon within 2 weeks because the fracture likely requires surgery. Can I get an appointment with an orthopaedic surgeon as soon as possible?" During the first stage of calls with the orthopaedic care provider, the caller reported having state-issued Medicaid correlating with the state and region in which the orthopaedic care provider practiced. Four weeks after the initial contact, the same orthopaedic offices were contacted and were subjected to the same interaction with the same caller. The sole difference with the second interaction was that the fictitious patient reported having Blue Cross Blue Shield Preferred Provider Organization coverage. In all instances of more detailed preappointment screenings, the caller stated that there were no legal issues surrounding the injury (disability and/or workers' compensation), claimed to have possession of ankle radiographs, reported current splinting of the injured ankle, and reported no chronic health issues.

\section{National Orthopaedic Practice Survey}

Orthopaedic practices operating in each state were contacted via telephone between February and April 2016 and surveyed regarding patient scheduling. The caller identified himself and disclosed that he was calling regarding a threequestion anonymous survey assessing patient access to care. The caller surveyed the practice using the following script algorithm: "Does your practice see adult patients with Medicaid insurance?" If the answer was "no," the caller asked if the responder knew why and then ended the call. If the answer was "yes," the caller asked "Does your office have any restriction on the number of adult patients with Medicaid that you see?" If the answer was "no," the call was ended. If the answer was "yes," the caller asked if the responder knew why and then ended the call. If the initial person who answered the phone was incapable of answering the questions posed, the office manager was requested, at which time the question sequence restarted from the beginning.

Variables, Outcome Measures, Data Sources, and Bias

\section{Participant-blinded Simulated Patient Survey}

All interactions with orthopaedic care providers were analyzed for the following outcomes: successful contact or failure to contact, acceptance or rejection of insurance coverage, appointment given within 2 weeks of call or appointment not given within 2 weeks of call, and the reason for lack of appointment or the earliest time at which an appointment could be made after the 2-week window. All calls to orthopaedic practices were made by the same caller and all data were recorded immediately after call completion. In any interactions in which the offices provided a tentative appointment on the condition that the patient present a Medicaid or private insurance identification number, emergency room records, or a primary care physician referral on arrival to the appointment or before appointment arrival, the researchers deemed this a successful appointment scheduling.

\section{National Orthopaedic Practice Survey}

All survey responses provided by participating orthopaedic practices were recorded. The relationship between practice type, Medicaid reimbursement, and Medicaid acceptance was examined. All calls to orthopaedic practice providers were made by the same caller and all data were recorded immediately after call completion. This survey study, based on work by Skaggs et al. [16], used three different Current Procedural Terminology $\left(\mathrm{CPT}^{\circledR}\right.$, American Medical Association, Chicago, IL, USA) codes as a representation of a physician's patient population; this included a new patient visit, a followup patient visit, and an 
Table 1. Summary of $\mathrm{CPT}^{\mathbb{B}}$ code reimbursement rate data

\begin{tabular}{|c|c|c|c|}
\hline \multirow[t]{2}{*}{ State } & \multicolumn{2}{|c|}{ Medicaid reimbursement rate } & \multirow[b]{2}{*}{$\mathrm{CPT}^{\circledR} 27786$} \\
\hline & $\mathrm{CPT}^{\circledR} 99243$ & $\mathrm{CPT}^{\mathbb{R}} 99213$ & \\
\hline AL & $\$ 86.00$ & $\$ 42.00$ & $\$ 212.00$ \\
\hline $\mathrm{AK}^{* *}$ & $\$ 201.65$ & $\$ 119.96$ & $\$ 507.67$ \\
\hline $\mathrm{AZ}^{* *}$ & $\$ 98.31$ & $\$ 51.25$ & $\$ 277.34$ \\
\hline $\mathrm{AR}^{* *}$ & $\$ 101.20$ & $\$ 36.30$ & $\$ 209.02$ \\
\hline $\mathrm{CA}^{* *}$ & $\$ 59.50$ & $\$ 24.00$ & $\$ 173.92$ \\
\hline $\mathrm{CO} * *$ & $\$ 87.80 *$ & $\$ 73.32$ & $\$ 105.21$ \\
\hline $\mathrm{CT} * *$ & $\$ 88.26$ & $\$ 25.74$ & $\$ 153.96$ \\
\hline $\mathrm{DE}^{* *}$ & $\$ 123.90^{*}$ & $\$ 72.59$ & $\$ 323.90$ \\
\hline FL & $\$ 139.05$ & $\$ 79.34$ & $\$ 171.70$ \\
\hline GA & $\$ 100.50$ & $\$ 40.70$ & $\$ 252.20$ \\
\hline $\mathrm{HI}^{* *}$ & $\$ 90.55$ & $\$ 36.31$ & $\$ 157.64$ \\
\hline ID & $\$ 108.35^{*}$ & $\$ 68.20$ & $\$ 264.33$ \\
\hline $\mathrm{IL}^{* *}$ & $\$ 51.30$ & $\$ 28.35$ & $\$ 152.60$ \\
\hline $\mathrm{IN}^{* *}$ & $\$ 82.55$ & $\$ 51.99$ & $\$ 224.24$ \\
\hline $\mathrm{IA}^{* *}$ & $\$ 90.55$ & $\$ 36.31$ & $\$ 157.64$ \\
\hline $\mathrm{KS}$ & $\$ 92.80 *$ & $\$ 53.87 *$ & $\$ 233.24 *$ \\
\hline $\mathrm{KY}^{* *}$ & $\$ 90.43$ & $\$ 42.63$ & $\$ 154.88$ \\
\hline LA** & $\$ 92.30 *$ & $\$ 60.51$ & $\$ 349.65$ \\
\hline ME & $\$ 77.77 *$ & $\$ 40.51$ & $\$ 172.52$ \\
\hline MD** & $\$ 115.89$ & $\$ 67.54$ & $\$ 282.06$ \\
\hline MA** & $\$ 73.29$ & $\$ 76.38$ & $\$ 309.22$ \\
\hline MI** & $\$ 68.34$ & $\$ 40.61$ & $\$ 178.49$ \\
\hline MN** & $\$ 94.92$ & $\$ 56.39$ & $\$ 222.70$ \\
\hline MS & $\$ 104.97 *$ & $\$ 43.52$ & $\$ 184.87$ \\
\hline MO & $\$ 74.49$ & $\$ 36.38$ & $\$ 225.56$ \\
\hline MT** & $\$ 122.41 *$ & $\$ 75.85$ & $\$ 337.84$ \\
\hline $\mathrm{NE}^{* *}$ & $\$ 88.44$ & $\$ 45.07$ & $\$ 162.87$ \\
\hline $\mathrm{NV}^{* *}$ & $\$ 116.40$ & $\$ 67.81$ & $\$ 201.08$ \\
\hline $\mathrm{NH}^{* *}$ & $\$ 72.80$ & $\$ 65.98$ & $\$ 225.80$ \\
\hline NJ** & $\$ 64.70$ & $\$ 23.50$ & $\$ 72.00$ \\
\hline $\mathrm{NM}^{* *}$ & $\$ 118.48$ & $\$ 50.52$ & $\$ 278.55$ \\
\hline NY** & $\$ 76.33$ & $\$ 37.41$ & $\$ 174.50$ \\
\hline $\mathrm{NC}$ & $\$ 99.91$ & $\$ 54.26$ & $\$ 212.65$ \\
\hline ND** & $\$ 88.48$ & $\$ 106.39$ & $\$ 465.78$ \\
\hline $\mathrm{OH}^{* *}$ & $\$ 53.41$ & $\$ 43.61$ & $\$ 163.66$ \\
\hline $\mathrm{OK}$ & $\$ 113.72 *$ & $\$ 58.86$ & $\$ 255.27$ \\
\hline $\mathrm{OR} * *$ & $\$ 87.05^{*}$ & $\$ 55.53$ & $\$ 222.58$ \\
\hline PA** & $\$ 59.94 *$ & $\$ 40.00$ & $\$ 118.50$ \\
\hline RI** & $\$ 37.00$ & $\$ 20.64$ & $\$ 67.20$ \\
\hline $\mathrm{SC}$ & $\$ 91.48$ & $\$ 45.37$ & $\$ 193.15$ \\
\hline SD & $\$ 97.79$ & $\$ 42.48$ & $\$ 270.54$ \\
\hline $\mathrm{TN}$ & $\mathrm{XX}$ & $\mathrm{XX}$ & $\mathrm{XX}$ \\
\hline $\mathrm{TX}$ & $\$ 80.23$ & $\$ 33.27$ & $\$ 239.77$ \\
\hline UT & $\$ 91.33$ & $\$ 52.74$ & $\$ 231.48$ \\
\hline VT** & $\$ 123.56$ & $\$ 58.14$ & $\$ 255.23$ \\
\hline VA & $\$ 84.39$ & $\$ 49.04$ & $\$ 277.24$ \\
\hline WA** & $\$ 73.51$ & $\$ 39.13$ & $\$ 190.04$ \\
\hline
\end{tabular}

Table 1. continued

\begin{tabular}{|c|c|c|c|}
\hline \multirow[t]{2}{*}{ State } & \multicolumn{2}{|c|}{ Medicaid reimbursement rate } & \multirow[b]{2}{*}{$\mathrm{CPT}^{\mathbb{R}} 27786$} \\
\hline & $\mathrm{CPT}^{\circledR} 99243$ & $\mathrm{CPT}^{\circledR} 99213$ & \\
\hline $\mathrm{WV} * *$ & $\$ 85.05$ & $\$ 49.88$ & $\$ 216.83$ \\
\hline WI & $\$ 122.32 *$ & $\$ 71.45^{*}$ & $\$ 310.56^{*}$ \\
\hline WY & $\$ 126.74$ & $\$ 67.36$ & $\$ 277.93$ \\
\hline
\end{tabular}

*Values obtained from Kaiser Foundation Medicaid-to-Medicare Fee Index; ** states that have expanded Medicaid; XX value unobtainable owing to statewide variation in $\mathrm{CPT}^{\mathbb{R}}$ code reimbursement via Medicaid; $\mathrm{CPT}^{\circledR}=$ current procedural terminology.

acute care patient visit. The reimbursement rates for $\mathrm{CPT}^{\circledR}$ codes 99213 (established followup outpatient visit - level 3 of 5), 99243 (new outpatient consultation - level 3 of 5), and 27786 (closed treatment of distal fibular fracture lateral malleolus - without manipulation - surgical care only) were determined at the time of the telephone survey via state Medicaid agency fee schedules for comparison to the responses attained via the telephone survey (Table 1). If the state Medicaid fee schedule did not provide the required information, the Kaiser Foundation Medicare-toMedicaid Fee Index was used to determine the associated $\mathrm{CPT}^{\mathbb{R}}$ code Medicaid reimbursement rates from known Medicare reimbursement rates $[6,10,17,20]$.

\section{Accounting for all Patients/ Study Subjects \\ Participant-blinded Simulated Patient Survey}

In total, 82 offices, including 21 in Pennsylvania, 21 in New Jersey, 17 in Delaware, and 23 in Maryland, were contacted for orthopaedic appointments. Of the 82 offices called, 18 were excluded from the study; one practice was specialized (TKA), three were nonsurgical (one in personal injury, two in physical therapy), two offices had closed, one practice did not return phone calls, and 11 (three in Pennsylvania, one in New Jersey, three in Maryland, and four in Delaware) did not answer calls or had disconnected phone lines. Sixty-four orthopaedic offices across Pennsylvania (15), New Jersey (19), Delaware (12), and Maryland (18) were included in the study (Table 2).

\section{National Orthopaedic Practice Survey}

Three hundred forty-two orthopaedic practices, seven from each state (two academic and five private), were included in the national survey study. Only three practices could be contacted in South Dakota and only six could be contacted in Connecticut, Delaware, Hawaii, and Vermont. 
Table 2. Results of the regional simulated patient survey for Medicaid acceptance and appointment scheduling

\begin{tabular}{|c|c|c|c|c|c|c|}
\hline Orthopaedic practice inclusion & PA & NJ & $\mathrm{DE}$ & MD & Total & $\%$ \\
\hline Total offices sampled & 21 & 21 & 17 & 23 & 82 & - \\
\hline Offices meeting study inclusion criteria & 15 & 19 & 12 & 18 & 64 & 100 \\
\hline Offices accepting Medicaid & 10 & 4 & 7 & 9 & 30 & 47 \\
\hline Offices providing Medicaid appointment within 2 weeks & 6 & 4 & 6 & 7 & 23 & 36 \\
\hline Offices accepting private insurance & 15 & 18 & 12 & 17 & 62 & 97 \\
\hline Offices providing private appointment within 2 weeks & 13 & 18 & 11 & 15 & 57 & 89 \\
\hline
\end{tabular}

Fig. 1 The observed orthopaedic practice appointment scheduling rates for the simulated patient survey, with the responses broken down by caller insurance status, are shown. Successful scheduling was defined as an appointment within 2 weeks from the time of call.

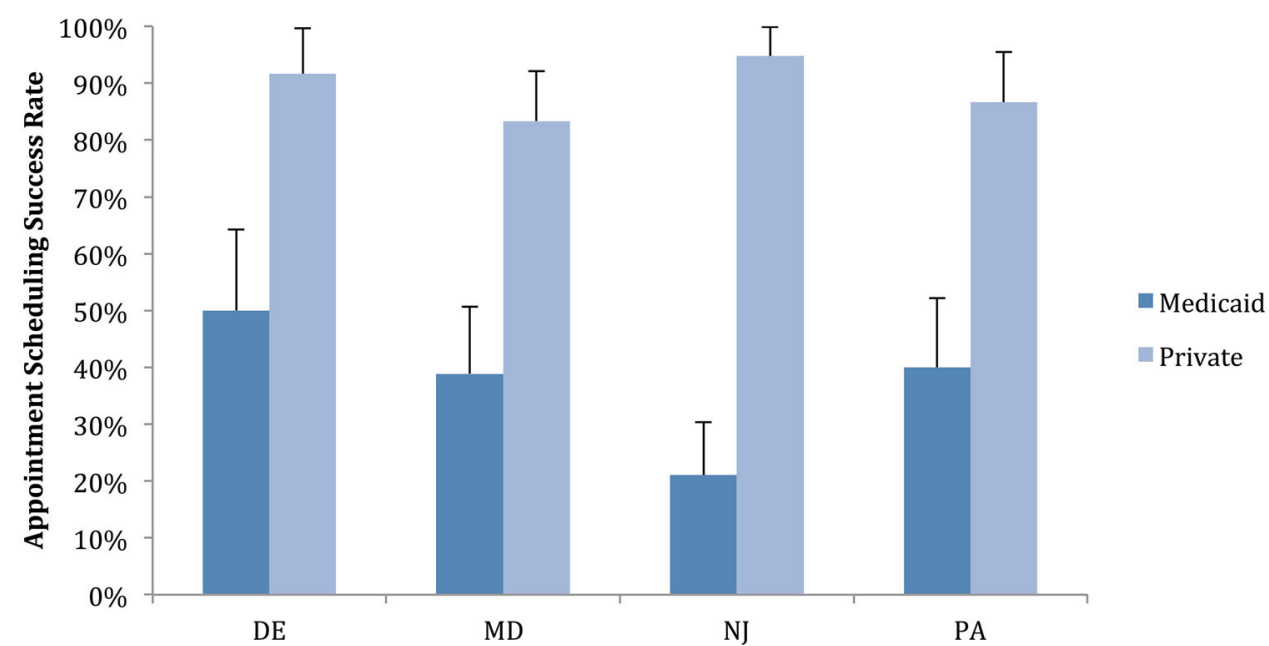

Statistical Analysis, Study Size

\section{Participant-blinded Simulated Patient Survey}

The paired categorical data generated via Medicaid and private insurance calls were statistically analyzed for asymmetry using McNemar's test, which is a chi-square test based on disjoint responses, that is, instances in which a practice provides different access to orthopaedic appointments depending on the form of insurance reported; the cases in which the practice accepts or rejects both forms are not informative [1]. A chi-square test was used to detect potential differences in Medicaid insurance acceptance rates across states sampled in the study. An alpha level of .05 was adopted to define statistically significant findings and subsequent rejection of the null hypothesis. Study size was based on a study by Pierce et al. [14].

\section{National Orthopaedic Practice Survey}

Univariate logistic regression was used to estimate how practice type (academic versus private) and Medicaid rate in the state affected the probability of the practice to accept patients with Medicaid insurance. Because the reimbursement rates for the three $\mathrm{CPT}^{\circledR}$ codes were correlated, they were each evaluated as predictors in separate regression models. All analyses were performed using the 'rms' package for the R statistical language (R Foundation for Statistical Computing, Vienna, Austria).

\section{Results}

(1) Do orthopaedic practices provide varying access to care based on health insurance?

\section{Simulated Patient Survey}

Offices were less likely to accept Medicaid than commercial insurance (30 of 64 [47\%] versus 62 of 64 [97\%]; odds ratio [OR], 0.01449; 95\% CI, 0.00088-0.23639; $\mathrm{p}<0.001$ ), and patients with Medicaid were less likely to be offered an appointment within 2 weeks (23 of 64 [36\%] versus 59 of 64 [89\%]; OR, 0.0154; $95 \% \mathrm{CI}$, 0.00094-0.251; $\mathrm{p}<0.001$ ) (Fig. 1). The Medicaid acceptance rates observed across states sampled in the simulated patient survey were 67\% (Pennsylvania), 21\% (New Jersey), 58\% (Delaware), and 50\% (Maryland) ( $\mathrm{p}=0.04$ ) (Fig. 2). 
Fig. 2 Insurance acceptance rates for the Medicaid and commercial-insured simulated patient with orthopaedic practice responses broken down by state are shown.

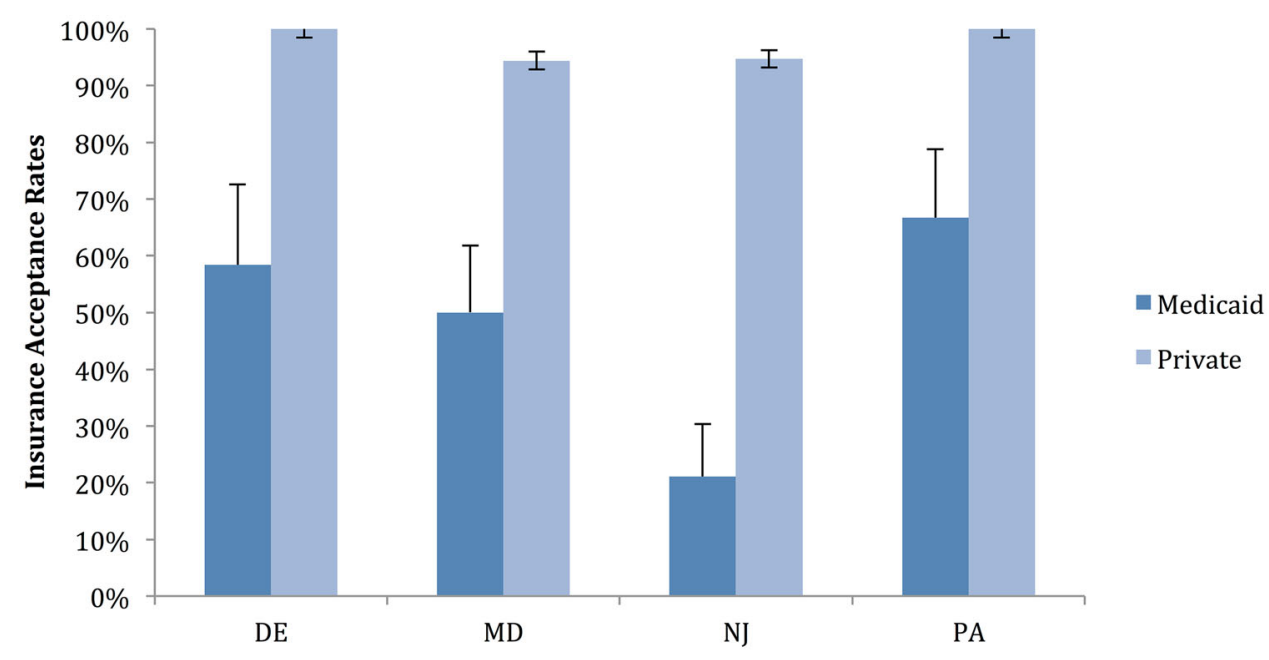

Table 3. Summary of access to healthcare data

\begin{tabular}{lllll}
\hline Practices & Number & Accept & Limit & Full access \\
\hline Total & 342 & 260 & 27 & 233 \\
Private & 271 & 194 & 23 & 171 \\
Academic & 71 & 66 & 4 & 62 \\
p Value & & $<0.001$ & 0.29 & $<0.001$ \\
\hline
\end{tabular}

\section{National Survey}

Of the 342 orthopaedic practices (ie, 271 private practices, 71 academic practices) contacted for this study, 260 (76\%) accepted adult patients with Medicaid, but only 233 do so without restriction $(68 \%)$ (Table 3$)$.

(2) What are the observed state Medicaid acceptance rates under Medicaid expansion?

\section{Simulated Patient Survey}

The Medicaid acceptance rates observed across states sampled in this survey were $66.6 \%$ in Pennsylvania (10/ 15), $21 \%$ in New Jersey (four of 19), $58.3 \%$ in Delaware (seven of 12), and $50 \%$ in Maryland (nine of 18) $(\mathrm{p}=0.04)$. However, the sample size of four states used in a chi-square analysis was insufficient to elicit these specific pairwise differences (Table 4).

\section{National Survey}

The Medicaid acceptance rates, by State, that were observed in this national survey varied from two of seven to seven of seven (Table 5). For the practices that limited or did not accept adult patients with Medicaid, the individual answering the phone most commonly did not know the reason why this policy was in place (78/109). The other common reasons for not accepting or limiting access of adult patients with Medicaid included emergency room patients only (three of 109), required referral (four of 109), managed care organization preference (eight of 109), caseby-case basis (eight of 109), physician preference in practice (six of 109), and children covered by Medicaid only (two of 109) (Table 6).

(3) Are Medicaid acceptance rates associated with reimbursement or practice type?

\section{National Survey}

The acceptance of Medicaid becomes increasingly more likely as the associated $\mathrm{CPT}^{\circledR}$ code reimbursement rates increase. Access to orthopaedic care in the adult orthopaedic patient population also varied in accordance with orthopaedic practice setting. The OR for $\mathrm{CPT}^{\circledR}$ reimbursement rate and the acceptance of Medicaid is 1.03 (95\% CI, 1.02-1.04) per dollar for 99243, 1.05 (95\% CI, 1.03-1.07) per dollar for 99213, and 1.01 (95\% CI, 1.00-1.01) per dollar for 28876 
Table 4. Simulated patient insurance acceptance rates

\begin{tabular}{|c|c|c|c|c|c|c|}
\hline Insurance status & State & Insurance denied & Insurance accepted & Acceptance rate & Standard error & p Value \\
\hline Medicaid & $\mathrm{DE}$ & 5 & 7 & $58 \%$ & $14 \%$ & $\mathrm{p}=0.04^{*}$ \\
\hline Medicaid & MD & 9 & 9 & $50 \%$ & $12 \%$ & \\
\hline Medicaid & NJ & 15 & 4 & $21 \%$ & $9 \%$ & \\
\hline Medicaid & PA & 5 & 10 & $67 \%$ & $12 \%$ & \\
\hline Private & DE & 0 & 12 & $100 \%$ & $0 \% \dagger$ & $\mathrm{p}=0.68$ \\
\hline Private & MD & 1 & 17 & $94 \%$ & $5 \%$ & \\
\hline Private & NJ & 1 & 18 & $95 \%$ & $5 \%$ & \\
\hline Private & PA & 0 & 15 & $100 \%$ & $0 \%{ }^{\dagger}$ & \\
\hline
\end{tabular}

$* \mathrm{~N}=4$ was insufficient to show specific pairwise differences despite $\mathrm{p}<0.05$ seen across states dealing with caller with Medicaid; ${ }^{\dagger}$ could not be calculated for $100 \%$ of entries (zero is a consequence of the formula).

$(\mathrm{p}<0.001)(99213=$ established followup outpatient visit level 3 of 5; $99243=$ new outpatient consultation - level 3 of 5 ; and $27786=$ closed treatment of distal fibular fracture lateral malleolus - without manipulation - surgical care only) (Table 7). Moreover, the OR for private versus academic practice setting and the acceptance of Medicaid is $0.11(95 \%$ CI, 0.04-0.33, p < 0.001) for CPT ${ }^{\circledR}$ code 99243, $0.11(95 \%$ CI, 0.04-0.32, p < 0.001) for $\mathrm{CPT}^{\circledR}$ code 99213, and 0.12 (95\% CI, 0.04-0.35, p < 0.001) for $\mathrm{CPT}^{\circledR}$ code 27786. Consequently, for a given reimbursement rate, private practices were less likely to take an adult patient with Medicaid insurance relative to an academic practice (Table 7).

Of the 260 institutions that accepted adult patients with Medicaid, 194 were considered private practice and 66 were considered academic practice. Thus, 72\% (194/271) of private practices and 93\% (66/71) of academic practices accepted adult patients with Medicaid (194 of 271 [72\%] versus 66 of 71 [93\%]; OR, 0.19; 95\% CI, 0.07-0.49; $\mathrm{p}<0.001$ ) (Table 3). Regarding the private practices that accepted adult patients with Medicaid, 12\% (23/194) imposed restrictions on the number of patients they see, leaving $63 \%$ of private orthopaedic practices using a fullaccess Medicaid model. Of the academic practices that accept adult patients with Medicaid, $6 \%$ (four of 66) imposed restrictions on the number of patients they see, leaving $87 \%$ of academic orthopaedic practices using a full-access Medicaid model. The difference between the number of private and academic practices that use this full-access model was noted (171 of 27 [64\%] versus 62 of 71 [87\%]; OR, 0.25; 95\% CI, 0.12-0.52; p < 0.001) (Table 3).

(4) Do patients in Medicaid-expansion States have better access to orthopaedic care?

\section{National Survey}

When we compared states that expanded Medicaid after the PPACA with those that did not, there was no difference in access to care for adult orthopaedic patients. This was true for all practice types (OR, 1.02; 95\% CI, 0.62-1.70; $\mathrm{p}=0.934)$, for academic practices alone (OR, 1.22; 95\% CI, 0.19-7.82; p = 0.84), and for private practices alone (OR, 1.02; 95\% CI, 0.59-1.76; $\mathrm{p}=0.94$ ) (Table 8). Thus, there was no difference, with the numbers available, in access to care for adult patients with Medicaid insurance based on whether their associated state had adopted PPACA Medicaid expansion.

\section{Discussion}

Adult patients with Medicaid insurance typically have faced substantial hurdles in obtaining timely care [3, 4, 7-9, 11, 13-16, 19]. Much of the impetus for the 2009 passage of the PPACA was an effort to address this [12]. However, there are little data regarding whether the expansion of coverage to previously uninsured groups has resulted in improved access or care. Since a majority of the almost 12 million newly insured have received their coverage through Medicaid, we sought to determine whether the new orthopaedic patients with Medicaid insurance would face fewer impediments to care. We found that inequality in access to orthopaedic care based on health insurance status likely exists in the adult patient population seeking care for an acute ankle fracture in state marketplaces with expanded Medicaid. Results from the national telephone survey study likely indicate that there is no difference in access to care for patients with Medicaid across states that have adopted Medicaid expansion versus states that have foregone Medicaid expansion. Additionally, we found that lower Medicaid reimbursement rates and the private practice setting (as opposed to academic practice) are associated with limited access to orthopaedic care in the adult population with Medicaid.

The researchers could not be blinded to the insurance status of the fictitious patient and/or the responses of the contacted practice. There is potential bias introduced by the 
Table 5. Summary of state-by-state Medicaid acceptance from the national survey study

\begin{tabular}{|c|c|c|c|}
\hline \multirow[t]{2}{*}{ State } & \multicolumn{3}{|c|}{ Medicaid acceptance rate (practice type) } \\
\hline & Private & Academic & Total \\
\hline $\mathrm{AL}$ & $4 / 5$ & $2 / 2$ & $6 / 7$ \\
\hline $\mathrm{AK}^{* *}$ & $6 / 6$ & $1 / 1$ & $7 / 7$ \\
\hline $\mathrm{AZ} * *$ & $5 / 6$ & $1 / 1$ & $6 / 7$ \\
\hline $\mathrm{AR}^{* *}$ & $5 / 6$ & $1 / 1$ & $6 / 7$ \\
\hline $\mathrm{CA}^{* *}$ & $1 / 5$ & $1 / 2$ & $2 / 7$ \\
\hline $\mathrm{CO} * *$ & $3 / 6$ & $1 / 1$ & $4 / 7$ \\
\hline $\mathrm{CT}^{* *}$ & $1 / 4$ & $2 / 2$ & $3 / 6$ \\
\hline $\mathrm{DE}^{* *}$ & $5 / 6$ & $\mathrm{xx}$ & $5 / 6$ \\
\hline FL & $2 / 5$ & $2 / 2$ & $4 / 7$ \\
\hline GA & $2 / 5$ & $2 / 2$ & $4 / 7$ \\
\hline $\mathrm{HI}^{* *}$ & $3 / 5$ & $1 / 1$ & $4 / 6$ \\
\hline ID & $7 / 7$ & $\mathrm{xx}$ & $7 / 7$ \\
\hline $\mathrm{IL}^{* *}$ & $3 / 5$ & $2 / 2$ & $5 / 7$ \\
\hline $\mathrm{IN}^{* *}$ & $5 / 6$ & $1 / 1$ & $6 / 7$ \\
\hline IA** & $5 / 6$ & $1 / 1$ & $6 / 7$ \\
\hline $\mathrm{KS}$ & $3 / 6$ & $1 / 1$ & $4 / 7$ \\
\hline $\mathrm{KY}^{* *}$ & $5 / 6$ & $1 / 1$ & $6 / 7$ \\
\hline $\mathrm{LA}^{* *}$ & $0 / 5$ & $2 / 2$ & $2 / 7$ \\
\hline ME & $7 / 7$ & $\mathrm{xx}$ & $7 / 7$ \\
\hline MD** & $4 / 5$ & $2 / 2$ & $6 / 7$ \\
\hline MA** & $5 / 5$ & $2 / 2$ & $7 / 7$ \\
\hline MI** & $4 / 5$ & $2 / 2$ & $6 / 7$ \\
\hline $\mathrm{MN}^{* *}$ & $5 / 5$ & $2 / 2$ & $7 / 7$ \\
\hline MS & $4 / 6$ & $1 / 1$ & $5 / 7$ \\
\hline MO & $0 / 5$ & $2 / 2$ & $2 / 7$ \\
\hline $\mathrm{MT}^{* *}$ & $7 / 7$ & $\mathrm{xx}$ & $7 / 7$ \\
\hline $\mathrm{NE}^{* *}$ & $5 / 5$ & $2 / 2$ & $7 / 7$ \\
\hline NV** & $2 / 6$ & $1 / 1$ & $3 / 7$ \\
\hline $\mathrm{NH}^{* *}$ & $5 / 6$ & $1 / 1$ & $6 / 7$ \\
\hline NJ** & $1 / 5$ & $2 / 2$ & $3 / 7$ \\
\hline $\mathrm{NM}^{* *}$ & $6 / 6$ & $1 / 1$ & $7 / 7$ \\
\hline NY** & $1 / 5$ & $2 / 2$ & $3 / 7$ \\
\hline $\mathrm{NC}$ & $5 / 5$ & $2 / 2$ & $7 / 7$ \\
\hline $\mathrm{ND}^{* *}$ & $7 / 7$ & $\mathrm{xx}$ & $7 / 7$ \\
\hline $\mathrm{OH}^{* *}$ & $2 / 5$ & $2 / 2$ & $4 / 7$ \\
\hline $\mathrm{OK}$ & $5 / 6$ & $1 / 1$ & $6 / 7$ \\
\hline $\mathrm{OR}^{* *}$ & $5 / 5$ & $2 / 2$ & $7 / 7$ \\
\hline $\mathrm{PA}^{* *}$ & $3 / 5$ & $1 / 2$ & $4 / 7$ \\
\hline $\mathrm{RI}^{* *}$ & $1 / 5$ & $1 / 2$ & $2 / 7$ \\
\hline $\mathrm{SC}$ & $3 / 5$ & $2 / 2$ & $5 / 7$ \\
\hline SD & $2 / 2$ & $1 / 1$ & $3 / 3$ \\
\hline $\mathrm{TN}$ & $4 / 5$ & $1 / 2$ & $5 / 7$ \\
\hline $\mathrm{TX}$ & $1 / 5$ & $1 / 2$ & $2 / 7$ \\
\hline UT & $5 / 6$ & $1 / 1$ & $6 / 7$ \\
\hline $\mathrm{VT}^{* *}$ & $5 / 5$ & $1 / 1$ & $6 / 6$ \\
\hline VA & $4 / 5$ & $2 / 2$ & $6 / 7$ \\
\hline
\end{tabular}

Table 5. continued

\begin{tabular}{llll}
\hline State & \multicolumn{3}{l}{ Medicaid acceptance rate (practice type) } \\
\cline { 2 - 4 } & Private & Academic & Total \\
\hline WA** $^{* *}$ & $5 / 6$ & $1 / 1$ & $6 / 7$ \\
WV $^{* *}$ & $4 / 5$ & $2 / 2$ & $6 / 7$ \\
WI & $4 / 5$ & $2 / 2$ & $6 / 7$ \\
WY & $7 / 7$ & $\mathrm{xx}$ & $7 / 7$
\end{tabular}

*Values obtained from Kaiser Foundation Medicaid-to-Medicare Fee Index; **states that have expanded Medicaid; $\mathrm{xx}=$ unobtainable owing to statewide variation in $\mathrm{CPT}^{\mathbb{R}}$ code reimbursement via Medicaid.

Table 6. Reasons for limited or no access to care

\begin{tabular}{ll}
\hline Reason & Number \\
\hline $\begin{array}{l}\text { Total number of practices that limit or do not accept } \\
\quad \text { Medicaid }\end{array}$ & 109 \\
Unknown reason why the practice limits/does not accept & 78 \\
$\quad$ Medicaid & 3 \\
Emergency room patients & 6 \\
Physician preference & 4 \\
Referral required & 8 \\
Patients with a specific Managed Care Organization only & 8 \\
Case-by-case basis & 2 \\
Only accepts children with Medicaid & \\
\hline
\end{tabular}

fictitious caller, which may artificially reduce the rate of appointment scheduling; practices might be more likely to appoint the same person if they were referred from a hospital where the practice is affiliated and provides call coverage, or if a referral came from an associated or known practice. The simulated patient survey construct was used to minimize potential researcher bias with the use of a script and identical presentation of information in preappointment screenings. The use of a fictitious patient in the simulated patient survey eliminated the potential for the office contacted to be aware of its participation in a research study, eliminating bias via the observer effect and allowing a more-accurate assessment of access to care. The sample size used in the simulated patient survey and national survey studies may be inadequate to show differences that truly exist, allowing the possibility of a Type II error. Calls were made consecutively and spaced over 4 weeks, which could have resulted in sampling bias owing to an unforeseen confounder. This was preferred over call randomization, as it was presumed that calls made to the same practice during a shorter interval may have introduced bias. The national survey study was limited by an inability to fully access participating practices' policy on Medicaid insurance acceptance. In many cases, the person 
Table 7. Private vs academic practice and Medicaid reimbursement for access to care

\begin{tabular}{|c|c|c|c|c|c|c|}
\hline \multirow[t]{2}{*}{$\mathrm{CPT}^{\circledR}$ code } & \multicolumn{3}{|c|}{ Private vs academic practice } & \multicolumn{3}{|c|}{ Medicaid reimbursement rate } \\
\hline & Odds ratio & $95 \% \mathrm{CI}$ & $\mathrm{p}$ Value & Odds ratio & $95 \% \mathrm{CI}$ & $\mathrm{p}$ Value \\
\hline 99243 & 0.11 & $(0.04-0.33)$ & $<0.001$ & 1.03 & $1.02-1.04$ & $<0.001$ \\
\hline 99213 & 0.11 & $(0.04-0.32)$ & $<0.001$ & 1.05 & $1.03-1.07$ & $<0.001$ \\
\hline 27786 & 0.12 & $(-0.04$ to 0.35$)$ & $<0.001$ & 1.01 & $1.00-1.01$ & $<0.001$ \\
\hline
\end{tabular}

Table 8. Medicaid acceptance in PPACA expansion states versus nonexpansion states

\begin{tabular}{llllr}
\hline Practice setting & $\begin{array}{l}\text { Expansion states } \\
\text { Medicaid acceptance }\end{array}$ & $\begin{array}{l}\text { Nonexpansion states } \\
\text { Medicaid acceptance }\end{array}$ & Odds ratio & 95\% CI Value \\
\hline Total & $167 / 220(76 \%)$ & $93 / 122(76 \%)$ & 1.02 & $0.62-1.70$ \\
Private & $125 / 175(71 \%)$ & $69 / 96(72 \%)$ & 1.22 & $0.19-7.82$ \\
Academic & $42 / 45(93 \%)$ & $24 / 26(92 \%)$ & 1.02 & $0.59-1.76$ \\
\hline
\end{tabular}

PPACA $=$ Patient Protection and Affordable Care Act.

completing the survey could not and/or would not provide explanations of the practices' Medicaid acceptance policies.

The results of our study corroborate those of previous studies, which consistently show that patients with Medicaid face increased challenges during the course of orthopaedic care; patients with Medicaid must travel farther to obtain orthopaedic care, wait a longer time before accessing care, are delayed in receiving the diagnosis of an acute orthopaedic injury, experience disruption in continuity of ambulatory care, and experience worse outcomes after surgery compared with patients with different health insurance [3, 9, 11, 19]. Pierce et al. [14] observed that the pediatric patients with Medicaid seeking outpatient care for an ACL tear before Medicaid expansion were 57 times less likely to receive an appointment within 2 weeks compared with a child with private insurance.

The results of the simulated patient survey study suggest that this inequality may be present to varying degrees on a state-by-state basis, as differences were observed in Medicaid acceptance rates among states surveyed. This was supported by our findings in the national survey, where access to orthopaedic care increased with increasing Medicaid reimbursement rates as well as the academic practice setting on a nationwide scale. Before the PPACA, Skaggs et al. [16] observed a state-by-state variation in access to care for pediatric orthopaedic patients, reporting that state-based access to care improved as state-determined physician reimbursement rates for treatment of a nondisplaced radius and ulna fracture without manipulation increased. Kim et al. [11] had similar findings, observing increased success in appointment scheduling for patients with Medicaid in states with a direct relationship between increased Medicaid reimbursement rates.
Our study and several others $[11,13,16]$ showed that limited access to orthopaedic care for the Medicaid population is associated with low physician reimbursement rates. While individuals responding to phone surveys in both studies rarely cited low Medicaid reimbursement as a reason to limit care, this correlation suggests that financial remuneration does play a role in access to orthopaedic care. Prevention of discrepancies in access to care attributable to reimbursement disparities between the Medicaid and private insurance populations is in part why the equal access provision of the Medicaid Act was implemented in the Social Security Act [18]. This requires physician reimbursement rates to be "sufficient to enlist enough providers so that services under the plan are available to recipients at least to the extent that those services are available to the general population" [18]. Despite this provision, the reimbursement rate disparity between private insurance and Medicaid continues to be substantial, as does the disparity between Medicaid and Medicare rates [10]. Additionally, for a given reimbursement rate, private practices were less likely to take an adult patient with Medicaid insurance relative to an academic practice.

Our national study found no difference in access to orthopaedic care between states that have adopted Medicaid expansion and those that have not. Lack of a prior study on access to orthopaedic care in Pennsylvania, New Jersey, Delaware, and Maryland before Medicaid expansion prevents us from quantifying the effects that Medicaid expansion has had on access to orthopaedic care in these states. The effects of Medicaid expansion on access to orthopaedic care are not fully understood. Patterson et al. [13] found that access to orthopaedic care was decreased in areas with high population density and areas in close proximity to an academic orthopaedic center. They posited 
that areas with high population density have a larger orthopaedic patient base, which may allow practices to operate with increasingly stringent patient-payer selection criteria while practices in less populous areas may lack this capability. Additionally, practices in areas of lower population density may feel uncomfortable informing patients of the need to travel long distances to seek care at an academic center [13]. However, Kim et al. [11] reported that patients with Medicaid pursuing orthopaedic appointments for primary TKA witnessed successful appointment scheduling rates of $22.8 \%$ in states foregoing Medicaid expansion and $37.7 \%$ in states with expanded Medicaid $(\mathrm{p}=0.011)$. Importantly, Kim et al. [11] also reported that patients with Medicaid seeking orthopaedic care in states with expanded Medicaid programs experienced longer waiting times for appointments obtained $(\mathrm{p}=0.001)$.

Patients with Medicaid insurance face a greater barrier to accessing a timely standard of care relative to patients with commercial health insurance. Unfortunately, this trend appears to have continued despite Medicaid expansion, likely indicating that increases in Medicaid coverage availability are not sufficient to increase access to orthopaedic care for the underinsured. Current expansions in Medicaid have likely realized minimal gains for the underinsured as policy has focused only on increasing the patient pool qualified for coverage. As more and more adults obtain coverage through Medicaid expansion and "compete" for a limited number of appointments, it may become more difficult for these patients to obtain an orthopaedic appointment. Policy aimed to improve access to care for orthopaedic patients with Medicaid must encourage greater Medicaid participation by orthopaedic surgeons. Although further research is needed to clearly delineate physician-patient-payer selection criteria, Medicaid reimbursement rates may need to be increased to incentivize the care of these patients and alleviate the pervasive inequality they experience in accessing orthopaedic treatment.

\section{References}

1. Altman DG. Practical Statistics for Medical Research. New York, NY: CRC Press; 1991.

2. Apfeld J, Han A, Stern T, Mir H, Obremskey WT, Jahangir AA, Sethi MK. Implications of the Supreme Court ruling on Medicaid. AAOS Now. 2012;6:20-24.

3. Baraga MG, Smith MK, Tanner JP, Kaplan LD, Lesniak BP. Anterior cruciate ligament injury and access to care in South Florida: does insurance status play a role? J Bone Joint Surg Am. 2012;94:e183.

4. Bisgaier J, Rhodes KV. Auditing access to specialty care for children with public insurance. N Engl J Med. 2011;363:23242333.
5. Centers for Medicare \& Medicaid Services. Medicaid \& CHIP: November 2015 Monthly Reports, Eligibility Determinations and Enrollment Report. January 2016. Available at: https://www. medicaid.gov/medicaid-chip-program-information/programinformation/downloads/november-2015-enrollment-report.pdf. Accessed March 3, 2016.

6. Clark BR. Medicaid access, rate setting, and payment suits: how the Obama administration is undermining its own health reform goals. Howard Law Journal. 2012;55:771-853. Available at: http://www.law.howard.edu/dictator/media/229/how_55_3_ revised.pdf. Accessed January 19, 2017.

7. Draeger RW, Patterson BM, Olsson EC, Schaffer A, Patterson $\mathrm{JM}$. The influence of patient insurance status on access to outpatient orthopedic care for flexor tendon lacerations. J Hand Surg Am. 2014;39:527-533.

8. Froelich JM, Beck R, Novicoff WM, Saleh KJ. Effect of health insurance type on access to care. Orthopedics. 2013;36:e12721276.

9. Hinman A, Bozic KJ. Impact of payer type on resource utilization, outcomes and access to care in total hip arthroplasty. $J$ Arthroplasty. 2008;23(6 suppl 1):9-14.

10. Huberfeld N. The Supreme Court ruling that blocked providers from seeking higher Medicaid payments also undercut the entire program. Health Aff (Millwood). 2015;34:1156-1161.

11. Kim CY, Wiznia DH, Hsiang WR, Pelker RR. The effect of insurance type on patient access to knee arthroplasty and revision under the Affordable Care Act. J Arthroplasty. 2015;30:14981501.

12. Musumeci M. A Guide to the Supreme Court's Decision on the ACA's Medicaid Expansion. Washington, DC: The Kaiser Commission on Medicaid and the Uninsured; August 2012. Available at: https://kaiserfamilyfoundation.files.wordpress.com/ 2013/01/8347.pdf. Accessed November 12, 2015.

13. Patterson BM, Draeger RW, Olsson EC, Spang JT, Lin PC, Kamath GV. A regional assessment of Medicaid access to outpatient orthopaedic care: the influence of population density and proximity to academic medical centers on patient access. $J$ Bone Joint Surg Am. 2014;96:e156.

14. Pierce TR, Mehlman CT, Tamai J, Skaggs DL. Access to care for the adolescent anterior cruciate ligament patient with Medicaid versus private insurance. J Pediatr Orthop. 2012;32:245-248.

15. Skaggs DL, Clemens SM, Vitale MG, Femino JD, Kay RM. Access to orthopedic care for children with Medicaid versus private insurance in California. Pediatrics. 2001;107: 1405-1408.

16. Skaggs DL, Lehmann CL, Rice C, Killelea BK, Bauer RM, Kay RM, Vitale MG. Access to orthopaedic care for children with Medicaid versus private insurance: results of a national survey. $J$ Pediatr Orthop. 2006;26:400-404.

17. The Henry J. Kaiser Family Foundation. State Health Facts: Medicaid-to-Medicare Fee Index. Available at: http://kff.org/ medicaid/state-indicator/medicaid-to-medicare-fee-index. Accessed February 102015.

18. USCODE 2010. 42 U.S.C. $\$ 1396 a$ (a)(30)(A).State plans for medical assistance. Available at: https://www.gpo.gov/fdsys/pkg/ USCODE-2010-title42/pdf/USCODE-2010-title42-chap7subchapXIX-sec1396a.pdf. Accessed January 19, 2017.

19. Wolinsky P, Kim S, Quackenbush M. Does insurance status affect continuity of care for ambulatory patients with operative fractures? J Bone Joint Surg Am. 2011;93:680-685.

20. Zuckerman S, Goin D. How Much Will Medicaid Physician Fees for Primary Care Rise in 2013? Evidence from a 2012 Survey of Medicaid Physician Fees. Kaiser Commission on Medicaid and the Uninsured. Available at: https://kaiserfamilyfoundation.files. wordpress.com/2013/01/8398.pdf. Accessed March 3, 2016. 